\title{
Study on Design of Intelligent Furniture and Application of Smart Material
}

\author{
Wei Xiao ${ }^{1 *}$, Yuan $\mathrm{Gao}^{2}$, and Xue-fang $\mathrm{Bai}^{3}$ \\ ${ }^{1}$ Fuyang Normal University, Fuyang, Anhui Province, PRC, 236041 \\ ${ }^{2}$ Anhui Polytechnic University, Wuhu, Anhui Province, PRC, 241000 \\ ${ }^{3}$ Fuyang Normal University, Fuyang, Anhui Province, PRC, 236041 \\ ${ }^{*}$ Corresponding author
}

\begin{abstract}
Keywords: Intelligent Furniture, Smart Material, Humanity, Interactive Features, Composite Materials.

Abstract. The exploration of intelligent furniture with its application is bound to cultivate a new economic growth point in China's furniture industry. When making possible a deep-level interaction between furniture and its users, intelligent furniture propels the innovation of furniture design. This allows furniture with rational thinking, fulfilling contemporary consumers' mental and physiological needs of high-quality life. One indispensible condition of intelligent furniture is the involvement of the new smart materials. The superior quality of the latter makes the former more aesthetic to look, more convenient and endurable to use, and more humanized to function.
\end{abstract}

\section{Introduction}

Intelligent furniture is the combination of traditional furniture and intelligent information technology, which, realizing "dialogue between human being and furniture", will make a new economic grown in furniture industry. Estimated according to "Prospect of Industry Development Environment and Market Demand Forecast Analysis Report of China's Smart Home Equipment, 2013", China's smart home industry will increase annually by $19.8 \%$, the value of production will reach RMB 124 billion yuan, and it's calculated that in the upcoming three years, the new increase in the market of China digital family is over RMB 50 billion yuan ${ }^{[1]}$. Currently, the typical intelligent furniture is the use of information technology, with the aid of which to control furniture terminal with application program. Meanwhile, some types of furniture become intelligent with smart materials. Any innovative form actually leads furniture industry into a new stage, where the design is more humanized and friendly to modern life with significant attention paid to people's mental and physiological needs.

\section{Types and Design Feature of Intelligent Furniture}

The hardware of intelligent furniture includes controller, hardware circuit, sensor, actuator and furniture while the software a series of system functions such as main program and data collection [2]. Consumers can manipulate the intelligent behavior of furniture via human-computer interface. The control commands are sent to all sections through interface circuit. The application program collects data by recognizing speech and image, and with somatosensory operation. The data are then short-distance transmitted into furniture terminal (sensor) to be analyzed and processed in cloud technology database. The data, also linkable to other hardware, can make remote controls and decisions to realize intelligent management and application, and offer service.

In China, intelligent furniture focuses on office furniture, and civil and public use. The intelligent office furniture is to join furniture pieces entirely with technology and information technology, including controlling system of office environment and multimedia, and monitoring system, such as intelligent file cabinet that presents the desired file only with inputting file code; those for civil use equally stress fast and convenient service, with particular functions developed for different targeted 
groups, like intelligent medicine cabinet which can warn against the outdated items; and the table for seniors, of which the desktop of adjustable height setting, dip and autorotation, ensures using comfort to relieve arm fatigue. Tables in-built with lighting can detect illumination intensity to provide proper light ray and time to avoid visual fatigue, controlling light sensation, postponing lighting off, and conducting timing switch. The installations of magnetic induction can automatically regulate temperature to keep a steady temperature [3]. Besides the adjustable height, the studying furniture for children is well consistent with the young psychological needs and their individual habits [4].

The intelligent series developed in cooperation by Lancas of Ireland, and universities from Germany, Sweden and Finland, covers sofa that can address welcoming speech, bookcase with smart alert to remind its owner of the overweight, and chest able to carry out auto- dehumidification and disinfection when the humidity within or some air index is exceeding the default. Italian cabinet producers have implanted into kitchen station function module similar to tablet PC, via which users can interact with the intelligent device by adjusting the setting of cold bin and the firepower of cooking range, and even by listening to music, watching video and seeking menu. The intelligent furniture, therefore, will revolutionize human life style, and bridge the direct communication between objects and people. With needs of special groups particularly met for public environment, it means barrier free design is promising in intelligent furniture design [5].

To sum up, intelligent furniture design, apart from the application of ergonomics to cater for user-object physiological relationship, emphasizes their constitutive relations more. Intelligent furniture, however, cannot neglect aesthetics and safety: they cannot be too fat, heavy, or big due to the existence of intelligent electrical apparatus; items like circuit board, mechanic device and electronic components, must be designed elusive and isolated with abundant heat dissipation and earth leakage protection. Problems of mechanical abrasion, and the erosion and aging of circuit must be taken into the scope of design [6].

\section{The Application of Smart Material in Furniture}

As a concrete cultural form, furniture is synthesis of art, martial and spirit. With the development of thousands of years, furniture has undertaken great changes in function, shape and material. With wood used mainly, traditional furniture uses natural materials of bamboo and vine, while materials for decorations are various, including natural marble, leather and metal. In an advanced age of science and technology, glass, plastic as well as artificial leather has been gradually applied most for furniture, i.e, furniture of pipe and canvas was made by Marcel Breue from The Bauhaus School of Design in the early 20th century. After World War II, furniture of composite plastic was popular among the public for their competitive price, bright color and fashion. The appearance of cermet in the 1950s marked the start of the age of composite. Then followed aluminium-plastic film and glass fiber reinforced plastics. Materials for furniture, at present, tend to be diverse, compound, green, and of high performance, better in line with one-time forming integration traits of fabricated part of modern furniture [7].

Innovative Development of Wood . Wood, if improved, is thus granted with more new functions. For example, a new honeycomb composite board has been produced abroad, which, bonded with artificial board, paper board, and recycled paper honeycomb core, is light and not easy to cause deformation. The interlayer has good effect of sound and thermal insulation, and absorbing shock, very beneficial to the development of furniture industrialization and automation [7]. The interactive lighting board, a plank added with new optical material, if used for flooring, responds to the pressure on its surface, and generates brightness that can linger and then decline gradually to exert a footprint effect; or if used with information technology, the board can yield various patterns and shadow effect once touched. Its appearance and mental property fits in very well with infant psychology, quite appropriate for Children's bedroom and surface for children's toys.

Intelligent glass . Modern furniture is smooth and easy in shape. Glass makes one good material for this type. The traditional tempered glass is of great hardness and resistant to elevated temperature. The streamlined nanometer diamond glass is stiff in character, of more metal quality 
and mirror effect. The kind of nanometer coating of carbon, similar in condition to diamond, feels comfort and smooth, leaves no fingerprint, and is able to bear weak acid and alkaline, and oxidation. It, of delicate and rational feature of high technology, is favored for external surface of domestic surface, freezer and microwave oven [8]. The intelligent visual-control glass can adjust vision immediately. It's made up of a layer of transparent glass and a layer of colored glass, with liquid crystal film between. Once the film is galvanized, the liquid crystal becomes arranged in order, making glass clear; with electronic current cut off, the crystal is released to reflect light all round, glass thereby becoming dim. This intelligent sort makes good alternative of window, enriching and adjusting environments of our life and work. Its individuality can shift easily a private area into one public. It can be used for doors and windows of sophisticated vehicles, outdoor screens, toys, gifts and lighting [8].

Intelligent metal material . Firm and good-looking, metal material is heavy, not resistant to erosion, and short of suppleness. Such demerits are solved with new metal materials. The new foam metal composite is made of metal and air hole, effectively reducing material density, with anti-pressure capacity greatly increased, good electric and heat conduction, and strong mechanical property. With exogenous process, the traditional metal material undertakes deformation, and with exogenous process gone, the shape is hard to restore. The shape memory alloy, however, can recover its original appearance with certain hot treatment for hundreds of times. When it is used for furniture, its mould can be kept, and furthermore, it can be overlaid for deposit, and then recover for use [8].

Additionally, there are other new smart materials anti-microbial, antifouling, and light-storage, which have been increasingly used for furniture. Anti-microbial cerement, and antifouling steel and fiber have hitherto been used for toys and electronic appliance. This type is urgently needed for bathroom accessories, and articles of daily use such as chairs and hangers. The Nanosphere coated fabric, developed in Switzerland with Nanoscale microporous technology, refuses any trace of water or blots like tomato pulp, honey, oil and blood. Obviously improving wearing quality and strength, the material with strong cleaning function has enjoyed a high price since it was launched into market in 2007. It makes a new environment-friendly material usable for home furnishings. The light-store material, used in intelligent furniture, generally employs solar battery that stores energy which is then released in form of light. Free of radiation and coating film, it's much greener for panel and furniture.

With the development of social economy and the improvement of life standard, more attention is attached to needs of particular groups. Furniture is inevitably oriented toward high-end consumers and special population with more qualitative service. Despite its late start, instability of technology, and comparatively brand influence, China's furniture is endowed with a new round of huge chances in the new market. The integration of traditional furniture with electronic information and new materials will subvert inherent perception into the furniture of China's furniture industry. Essential for development of composite materials and compound furniture design are talents of versatility and innovation. The design field of intelligent furniture, no doubt, will be greatly challenging for product designers in this age.

\section{Conclusions}

The intelligent furniture has been increasingly used in the world, while its trend in China is yet to come. Only with its recognition that's promoted with the aid of research by academic circle, can its popularity be expected, and then can more items of intelligent furniture find their access into life of more average people.

\section{Acknowledgement}

This research was financially supported by the Major Project of Humanities \& Social Science, Education Department of Anhui Province (SK2016SD48), Major Instruction Reform Project of Revitalization Plan, Education Department of Anhui Province (2015zdjy196), Project of National 
Innovation and Entrepreneurship Training Program of Undergraduate(201513619001), and one of the achievements of Key Project of Humanities \& Social Science, Education Department of Anhui Province (SK2015A724).

\section{References}

[1] K.J. Tang, Xiang PENG, Analysis of Furniture Intelligence Ecosystems, J. Furniture and Interior Design, 4(2015): 12-14.

[2] Y. Cao, Study on Intelligent Children Furniture, J. Academic Dissertation of Northwest Agriculture \& Forestry University, 5 (2009)212-214.

[3] X. L. Li. Study on Design System of Intelligent Senile Furniture, J. Art and Design, 9(2012)212-213.

[4] S. Y, Xiang WANG, Trend of Furniture Design in the $21^{\text {st }}$ Century, J. Journal of Northeast Forestry University, 29 (2001)83-84.

[5] H. L. Wang, New Concept of Furniture Design, J. Timber Industry, 1(2006) 32-35.

[6] J.C. Hu, Xiang-dong DAI, Introduction to Furniture Design. Beijing: China Forestry Publishing House, 1999.

[7] S. R. Niu, Architectural analysis and Choice of Future Furniture Material, J. Academic Dissertation of Yan Shan University, 5(2013)33-38.

[8] N. Yu, Applied Research of New Material and Process Oriented toward Industry Design, J. Master Thesis of Harbin University of Science and Technology, 3(2009)27-35. 